\title{
Gaps in public preparedness to be a substitute decision-maker and the acceptability of high school education on resuscitation and end-of-life care: a mixed-methods study
}

\author{
Michael K.Y. Wong MD, Maria Cassandre Medor BHSc, Katerina Yelle Labre BScHK, \\ Mengzhu Jiang MD MSc, Jason R. Frank MD MA(Ed), Lisa M. Fischer MD, \\ Warren J. Cheung MD MMEd
}

\section{Abstract}

Background: When a patient is incapable of making medical decisions for him- or herself, a substitute decision-maker makes choices according to the patient's previously expressed wishes, values and beliefs; however, little is known about public readiness to act as a substitute decision-maker in Canada. Our primary objective was to measure public self-reported preparedness to act as a substitute decision-maker, and explore the attitudes, barriers and enablers associated with preparedness.

Methods: From November 2017 to June 2018, we conducted a mixed-methods street intercept survey at 12 pedestrian areas in Ottawa, Ontario. We used descriptive statistics and logistic regression analysis to assess predictors of perceived preparedness to be a substitute decision-maker and determine support for high school education. We analyzed qualitative interview questions using inductive thematic analysis.

Results: Of the 626 eligible respondents, 196 refused to participate, leaving 430 participants (response rate $68.7 \%$ ). A total of 404 surveys $(94.0 \%)$ were fully complete with no missing data. The respondents were mostly female (243 [56.5\%]) and residents of Ontario (364 [84.6\%]). The average age was 33.9 years. Although 314 respondents $(73.0 \%)$ felt prepared to be a substitute decisionmaker, $194(45.1 \%)$ reported never having had meaningful conversations with loved ones to understand their wishes in the event of critical illness. A total of 293 participants (68.1\%) identified important barriers to feeling prepared. Most respondents (309 [71.9\%]) agreed that high school students should learn about being a substitute decision-maker, citing age appropriateness, potential societal benefit and improved decision-making, while cautioning the need to respect different maturity levels, cultures and experiences.

Interpretation: The lack of conversation between loved ones reveals a gap between perceived and actual preparedness to be a substitute decision-maker for a loved one with a critical illness. The overall acceptability of high school education warrants further exploration.

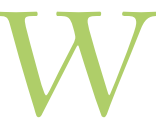

hen patients are incapable of making decisions for their own medical care, choices are made by their substitute decision-maker in the spirit of their previously expressed wishes, values and beliefs. ${ }^{1}$ Conforming to an established advance care plan is associated with better quality of life for patients, positive emotional outcomes for families and reduced use of health care resources near the end of life. ${ }^{2-5}$ Too often, however, patient wishes have not been addressed ahead of time, a default substitute decision-maker is appointed ad hoc per a hierarchy established in most provinces, and these conversations become particularly challenging in the time pressures of critical illness. Such decisions are increasingly common with an aging demographic: in one US study, $67.8 \%$ of patients more than age 65 years required a decision made by substitute decision-makers within 48 hours of admission to hospital. 6 Many barriers to having these conversations remain, and errors are common. ${ }^{7,8}$
Although there are many studies that report interventions to engage patients in their own advance care plan, ${ }^{9}$ none have described public readiness to act as a substitute decisionmaker on behalf of patients. Our primary objective was to measure public self-reported preparedness to act as a substitute decision-maker, and explore the attitudes, barriers and enablers associated with preparedness. Second, we aimed to quantify public support for a population-level curriculum centred on substitute decision-making in end-of-life and resuscitative care.

Competing interests: None declared.

This article has been peer reviewed.

Correspondence to: Michael Wong, miwong @ toh.ca

CMAJ Open 2019. DOI:10.9778/cmajo.20190037 


\section{Methods}

\section{Study design}

This was a mixed-methods, cross-sectional public intercept survey. Being prepared as a substitute decision-maker is a health behaviour; thus, the development of the survey was informed by the Health Belief Model, which describes how personal characteristics (e.g., age, gender, income), perceived susceptibility, benefits and barriers, and cues to action predict engagement in a health behaviour. ${ }^{10} \mathrm{We}$ used our collective expertise in emergency medicine, family medicine, education and palliative care to refine the questions. To our knowledge, no validated measure of preparedness exists, and, given that self-perception underlies behaviour, we chose self-reported preparedness as our primary outcome.

\section{Setting}

The survey was conducted in Ottawa, Ontario from November 2017 to June 2018 at 12 locations with high pedestrian traffic, chosen to represent geographically and economically disparate regions of the city (Box 1). Previous street intercept studies on health behaviour attitudes have targeted similar locations to maximize diversity. ${ }^{11}$

\section{Participants and sampling}

Our target population was the population of Ottawa. Participants were included if present in the study area and aged 16 years or more, the minimum age to act as a substitute decision-maker in Ontario. Potential participants were excluded if they were not residents of Canada, were unable to communicate in English or French, or were unable to provide informed consent. We also excluded those doing activities inappropriate to interrupt (i.e., working, exercising) or in groups of 3 or more.

For the quantitative analysis, we estimated the sample size needed using Cochran's formula for large populations. ${ }^{12}$ Based on a $95 \%$ confidence interval (CI), $5 \%$ margin of error and an estimated proportion of 0.5 , the minimum sample size needed was 385 . We chose a priori to continue data collection to 400 fully complete surveys.

\section{Box 1: The 12 data collection locations}

1. Rideau Centre (bus station and mall)

2. Byward Market (tourist area/outdoor market/inner city area)

3. World Exchange Plaza (high-density corporate area with restaurants)

4. Lansdowne (outdoor shopping area/restaurant hub)

5. Bayshore (bus station and mall)

6. Place d'Orléans (bus station and mall)

7. University of Ottawa (bus station and campus)

8. St. Laurent (bus station and mall)

9. Mooney's Bay (public park/beach)

10. Billings Bridge (bus station and mall)

11. Britannia Beach (public park/beach)

12. Tanger Outlets (suburban mall)

\section{Questionnaire}

We optimized the survey according to the methods described by Dillman and colleagues. ${ }^{13}$ That is, the brevity and anonymity of our survey, along with its standardized verbal prompts for participants to elaborate, were designed to maximize response rate and qualitative detail. The questionnaire (Appendix 1, available at www.cmajopen.ca/content/7/3/ E573/suppl/DC1) was then pilot tested among 15 volunteers (acquaintances of the authors with no medical or health care background) and revised for clarity.

Participants provided basic demographic characteristics and indicated whether they were a health care provider. Questions explored self-reported preparedness to be a substitute decision-maker in the context of critical illness or end of life, including open-ended questions that asked participants to describe barriers to and enablers of their own preparedness. Respondents were also asked about the acceptability of an educational intervention for 16-year-old students regarding substitute decision-makers and critical and end-of-life care. We probed open-ended questions using standardized verbal prompts for clarity and detail.

We chose this triangulation mixed-methods design to deepen and broaden our understanding of the attitudes and beliefs beyond demographic and experiential factors.

\section{Data collection and procedures}

Each location was visited 3-4 times for 2 hours at a time. We used a random-number generator to evenly distribute start times between 0700 and 1900 among the 12 locations. At each excursion, pairs of investigators approached every third person in the area using a standardized script. Potential participants were told that the interviewers were a resident physician and medical students conducting research to explore enablers and barriers associated with being a substitute decision-maker and that the survey would take 10 minutes to complete. After consent was obtained, the survey was completed in English or French and in verbal or written format according to participant preference. All participants were asked to answer all quantitative and qualitative survey elements. The 2 investigators transcribed verbal answers and recorded field notes if a participant elaborated verbally on written answers. Participants approved final answers and field notes.

\section{Quantitative analysis}

We analyzed participant sociodemographic characteristics and responses to binary and Likert scale questions descriptively. For Likert scale items, we constructed binary variables by grouping "Agree" and "Strongly agree" together, and "Neutral," "Disagree" and "Strongly disagree" together. We presented sociodemographic characteristics and responses to other questions descriptively, stratified by the 2 main outcome variables, self-reported substitute decision-maker preparedness and acceptability of an education intervention. We conducted multivariate logistic regression for these 2 outcomes with covariates selected a priori by consensus. For substitute decision-maker preparedness, selected predictor variables included sociodemographic characteristics, previous experience as a 
substitute decision-maker, having engaged in advance care planning for oneself, belief that one will have to act as a substitute decision-maker someday, having had a conversation with loved ones about their values and comfort in initiating a conversation. For belief that 16 -year-olds should be taught about substitute decision-makers, the selected predictor variables included sociodemographic characteristics, substitute decisionmaker preparedness, having engaged in advance care planning for oneself, previous experience as a substitute decision-maker, belief that one will have to act as a substitute decision-maker someday, having had a conversation with loved ones about their values and belief that substitute decision-making is a learnable skill. Data points with missing data on either the independent or dependent variables were excluded from the multivariate analysis. Model assumptions, including absence of collinearity for the independent variables and an appropriate number of covariates for our sample size, were confirmed to be apt. We conducted all statistical analyses using SAS 9.4 software (SAS Institute).

\section{Qualitative analysis}

Following the approach described by Braun and Clarke, ${ }^{14}$ 2 independent reviewers (M.K.Y.W. and W.J.C.) conducted inductive thematic analysis for open-ended questions that explored perceived enablers of and barriers to acting as a substitute decision-maker and whether 16-year-old students should learn about resuscitation, end-of-life care and being a substitute decision-maker. The 2 reviewers conducted line-by-line coding of all field notes and survey responses. Through joint discussions between the 2 reviewers, codes were synthesized and general themes identified. Data saturation was defined as no new themes identified after 5 consecutive interviews. Integration of the qualitative and quantitative results occurred during data interpretation and manuscript preparation.

\section{Ethics approval}

This study was approved by the Ottawa Hospital Research Institute Ethics Board. Consent was obtained verbally through a standardized script (Appendix 1).

\section{Results}

A convenience sample of dates with a total of 31 weekday and 9 weekend-day excursions was necessary to reach the target sample size. Of the 873 people encountered, 217 were excluded owing to activity (e.g., running, working; 185) or group size ( $\geq 3$ people; 32$)$. The remaining 656 people were approached, of whom 30 were excluded (because of country of residence in 13 cases, language barrier in 11 and ineligible age in 6). Of the remaining 626 people, 196 refused to participate (time constraints in 97 cases, not interested in 76 and reason unknown in 23), leaving 430 participants, for an overall response rate among eligible participants of $68.7 \%$. A total of 404 surveys (94.0\%) were fully complete with no missing data, and no individual question had a missing data rate greater than 3.5\% (Appendix 2, available at www.cmajopen.ca/ content/7/3/E573/suppl/DC1).
Overall, our sample had an average age of 33.9 years, and there was a slight preponderance of female participants (243 [56.5\%]) (Table 1). A total of 359 respondents $(83.5 \%)$ had completed at least some college/university. Most respondents were residents of Ontario (364 [84.6\%]) or Quebec (52 $[12.1 \%])$. Sixty-seven respondents (15.6\%) had previously acted as a substitute decision-maker for an adult loved one. The youngest respondent with substitute decision-maker experience was 18 years old. About one-third of respondents (137 [31.9\%]) had previously created advance care plans for themselves.

\section{Substitute decision-maker preparedness}

Although 314 respondents (73.0\%) felt prepared to be a substitute decision-maker, 127 (40.4\%) of those prepared and

\begin{tabular}{|c|c|}
\hline Characteristic & $\begin{array}{c}\text { No. }(\%) \text { of } \\
\text { respondents } \\
n=430\end{array}$ \\
\hline \multicolumn{2}{|l|}{ Age, yr } \\
\hline $16-17$ & $23(5.3)$ \\
\hline $18-34$ & $253(58.8)$ \\
\hline $35-49$ & $62(14.4)$ \\
\hline $50-64$ & $53(12.3)$ \\
\hline$>64$ & $36(8.4)$ \\
\hline Missing & $3(0.7)$ \\
\hline \multicolumn{2}{|l|}{ Gender } \\
\hline Female & $243(56.5)$ \\
\hline Male & $186(43.3)$ \\
\hline Other & $1(0.2)$ \\
\hline Health care professional & $34(7.9)$ \\
\hline \multicolumn{2}{|l|}{ Province of residence } \\
\hline Ontario & $364(84.6)$ \\
\hline Quebec & $52(12.1)$ \\
\hline Other & $8(1.9)$ \\
\hline Missing & $6(1.4)$ \\
\hline \multicolumn{2}{|l|}{ Education } \\
\hline Did not complete high school & $20(4.6)$ \\
\hline High school diploma & $49(11.4)$ \\
\hline Some college/university & $124(28.8)$ \\
\hline College/university diploma & $166(38.6)$ \\
\hline $\begin{array}{l}\text { Working on/completed postgraduate } \\
\text { studies }\end{array}$ & $48(11.2)$ \\
\hline Professional degree & $21(4.9)$ \\
\hline Missing & $2(0.5)$ \\
\hline $\begin{array}{l}\text { Previously acted as substitute decision- } \\
\text { maker }\end{array}$ & $67(15.6)$ \\
\hline $\begin{array}{l}\text { Previously created advance care plan for } \\
\text { self }\end{array}$ & $137(31.9)$ \\
\hline
\end{tabular}


$194(45.1 \%)$ of all respondents had never had a meaningful conversation about their loved one's wishes in the event of critical illness. Three-quarters of respondents believed that they would act as a substitute decision-maker in the future (325 [75.6\%]) and felt comfortable initiating a conversation with loved ones about values in critical illness (318 [74.0\%]). Most (358 [83.3\%]) believed that having such conversations is a learnable skill.

Figure 1 shows rates of self-reported preparedness to be a substitute decision-maker by demographic characteristics and selected predictor variables. There was a trend toward higher rates of self-reported preparedness among older participants, health care professionals, those who reported previous substitute decision-maker experience, those with previous advance care planning experience and those who believed that they would act as a substitute decision-maker in the future. The rate of preparedness was higher among participants who had had a previous conversation with loved ones about their wishes in a critical care scenario than among those who had not had such conversations; however, the difference was not significant (odds ratio [OR] 1.23, 95\% CI 0.72-2.08). Only 2 factors were significantly associated with preparedness to be a substitute decision-maker: age 50-64 versus 16-18 (OR 7.46, 95\% CI 1.25-44.51) and the belief that one would have to act as a substitute decision-maker in the future (OR 2.36, 95\% CI 1.34-4.17) (Table 2).
Although we analyzed all 430 interviews, data saturation was achieved at the 80th interview. Enablers and barriers associated with preparedness to be a substitute decision-maker and representative quotations, by theme, are shown in Table 3. Key enablers included an understanding of a loved one's preexisting wishes, the role of the substitute decisionmaker and its legal framework, the medical information, strong relationships among the substitute decision-maker, patient and family, and trust in the medical team. A total of 293 participants $(68.1 \%)$ identified barriers to preparedness, which included potential for family conflict, the daunting nature of high-stakes decisions, social or cultural barriers to communication, and need for time and a quiet setting. Many respondents with previous substitute decision-maker experience reported difficulty knowing how to prepare for such a difficult life event.

\section{Support for population-level education}

A total of 309 respondents (71.9\%) (including 22/23 of those aged 16-17) believed that 16-year-olds should learn about substitute decision-makers for resuscitation and endof-life care, 65 (15.1\%) were neutral, and 41 (9.5\%) disagreed. Principally, there was strong agreement between those who believed such topics "can" versus "should" be taught (Spearman's correlation coefficient 0.60). There was a trend toward agreeing with high school education among

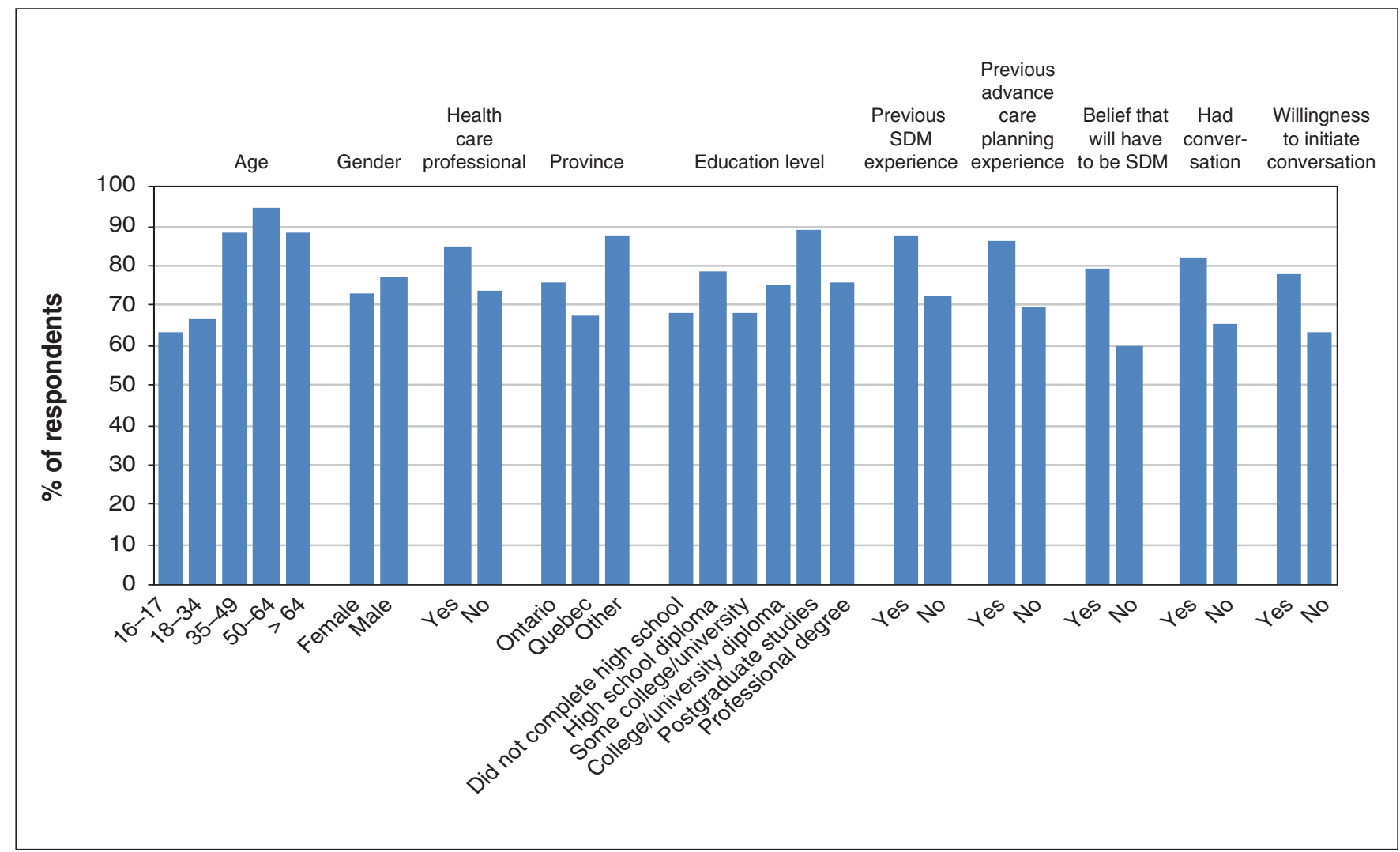

Figure 1: Rates of self-reported preparedness to be a substitute decision-maker (SDM) for a loved one with a critical illness, by demographic characteristics and selected predictor variables. Note: conversation refers to conversation regarding the wishes of loved ones in the event of critical illness or end of life. 


\begin{tabular}{|c|c|c|}
\hline \multirow[b]{2}{*}{ Variable } & \multicolumn{2}{|c|}{ OR $(95 \% \mathrm{Cl})$} \\
\hline & $\begin{array}{c}\text { Self-reported } \\
\text { preparedness to act as } \\
\text { substitute decision-maker } \\
\text { for adult loved one }\end{array}$ & $\begin{array}{l}\text { Belief that } 16 \text {-year-olds should } \\
\text { learn about resuscitation and } \\
\text { end of life }\end{array}$ \\
\hline \multicolumn{3}{|l|}{ Age, yr } \\
\hline $16-17$ & Reference & Reference \\
\hline $18-34$ & $1.13(0.30-4.17)$ & $0.11(0.01-1.16)$ \\
\hline $35-49$ & $3.29(0.69-15.57)$ & $0.07(0.01-0.78)$ \\
\hline $50-64$ & $7.46(1.25-44.51)$ & $0.10(0.01-1.08)$ \\
\hline$>64$ & $3.44(0.64-18.52)$ & $0.11(0.01-1.23)$ \\
\hline \multicolumn{3}{|l|}{ Gender } \\
\hline Female & Reference & Reference \\
\hline Male & $1.64(0.98-2.74)$ & $1.16(0.71-1.89)$ \\
\hline \multicolumn{3}{|l|}{ Health care professional } \\
\hline Yes & $1.74(0.53-5.75)$ & $0.67(0.28-1.59)$ \\
\hline No & Reference & Reference \\
\hline \multicolumn{3}{|l|}{ Province } \\
\hline Ontario & Reference & Reference \\
\hline Quebec & $0.53(0.26-1.08)$ & $1.02(0.50-2.07)$ \\
\hline Other & $1.70(0.19-15.14)$ & $1.16(0.20-6.87)$ \\
\hline \multicolumn{3}{|l|}{ Education } \\
\hline Did not complete high school & Reference & Reference \\
\hline High school diploma & $0.76(0.18-3.24)$ & $1.30(0.20-8.62)$ \\
\hline Some college/university & $0.86(0.20-3.70)$ & $1.01(0.16-6.23)$ \\
\hline College/university diploma & $0.66(0.15-2.90)$ & $1.22(0.20-7.52)$ \\
\hline $\begin{array}{l}\text { Working on or completed } \\
\text { postgraduate studies }\end{array}$ & $1.46(0.25-8.43)$ & $0.90(0.13-6.02)$ \\
\hline Professional degree & $0.35(0.05-2.29)$ & $1.24(0.15-10.11)$ \\
\hline $\begin{array}{l}\text { Previously acted as substitute } \\
\text { decision-maker }\end{array}$ & $0.98(0.37-2.57)$ & $0.77(0.37-1.60)$ \\
\hline $\begin{array}{l}\text { Previously participated in advance care } \\
\text { planning for self }\end{array}$ & $2.01(1.06-3.83)$ & $1.71(0.96-3.07)$ \\
\hline $\begin{array}{l}\text { Belief that one will have to act as } \\
\text { substitute decision-maker }\end{array}$ & $2.36(1.34-4.17)$ & $1.90(1.07-3.37)$ \\
\hline $\begin{array}{l}\text { Had previous conversation with loved } \\
\text { ones about wishes in critical illness }\end{array}$ & $1.23(0.72-2.08)$ & $1.20(0.72-2.01)$ \\
\hline $\begin{array}{l}\text { Willing to initiate conversation with } \\
\text { loved ones about wishes in critical } \\
\text { illness }\end{array}$ & $1.47(0.84-2.57)$ & - \\
\hline $\begin{array}{l}\text { Belief that having conversation with } \\
\text { loved ones about wishes in critical } \\
\text { illness is learnable skill }\end{array}$ & - & $2.57(1.37-4.80)$ \\
\hline Self-reported preparedness & - & $0.98(0.55-1.74)$ \\
\hline
\end{tabular}


Table 3: Self-reported enablers of and barriers to preparedness to be a substitute decision-maker

\begin{tabular}{|c|c|c|}
\hline Theme & Subtheme & Representative quotation \\
\hline Real-life experience & $\begin{array}{l}\text { Difficulty in knowing how to prepare } \\
\text { oneself }\end{array}$ & $\begin{array}{l}\text { "My mother had advanced dementia. When [she died], we did } \\
\text { not know what to expect. We wanted her to be comfortable, but } \\
\text { she didn't look comfortable [when she died]. If we had known } \\
\text { how difficult it would be to watch [cardiopulmonary resuscitation], } \\
\text { we would have stopped. [We need] more guidelines on how to } \\
\text { prepare oneself. What questions to ask a parent. We thought we } \\
\text { were prepared and we weren't.... We really didn't know what } \\
\text { questions to ask." ( } 62 \text { yr-old woman [describing her experience } \\
\text { with changing the code status of her parent from Do not } \\
\text { resuscitate to full code as she died]) }\end{array}$ \\
\hline $\begin{array}{l}\text { Information necessary for } \\
\text { decision-making }\end{array}$ & $\begin{array}{l}\text { Understanding preexisting wishes } \\
\text { through such means as conversation, } \\
\text { living wills }\end{array}$ & $\begin{array}{l}\text { "I watched my dad go through this with my grandfather and he } \\
\text { had Alzheimer's, but they had discussed this sort of things } \\
\text { beforehand, so it made things a lot easier on him because he } \\
\text { already knew what my grandfather wanted and how to handle } \\
\text { the situation." (31-yr-old man) }\end{array}$ \\
\hline Understanding role of SDM & $\begin{array}{l}\text { Understanding capacity and SDM } \\
\text { legislation } \\
\text { Clarity regarding who legal SDM is } \\
\text { Voluntary nature of being SDM } \\
\text { No secondary gain }\end{array}$ & $\begin{array}{l}\text { "Need to have legal rights [explained], especially if you were to } \\
\text { come [to] odds with the medical team." (47-yr-old man) } \\
\text { "It's not clear what we expect from the SDM - it's important to } \\
\text { know and understand the different options that are available to } \\
\text { help guide the SDM." (66-yr-old man) }\end{array}$ \\
\hline $\begin{array}{l}\text { Relationships among SDM/ } \\
\text { patient/family }\end{array}$ & $\begin{array}{l}\text { Fear of family conflict and social } \\
\text { pressures } \\
\text { Family consensus }\end{array}$ & $\begin{array}{l}\text { "We [made] some bad decisions for my mother trying to keep } \\
\text { some of my siblings happy. ... Experience is a huge factor in } \\
\text { empathy and understanding, and differentiating between what a } \\
\text { loved one is saying and what [he or she] needs." (62-yr-old } \\
\text { woman) }\end{array}$ \\
\hline Attributes of SDM & $\begin{array}{l}\text { Maturity, strong value system } \\
\text { Willingness to separate personal and } \\
\text { loved one's values } \\
\text { Previous life experience } \\
\text { Ability to act rationally despite distress } \\
\text { of situation }\end{array}$ & $\begin{array}{l}\text { "[You] need to be a good listener so you can understand the } \\
\text { situation, need to be considerate of what the loved one would } \\
\text { want, need to be rational and not too emotional." (42-yr-old } \\
\text { woman) }\end{array}$ \\
\hline $\begin{array}{l}\text { Relationship with medical } \\
\text { team }\end{array}$ & $\begin{array}{l}\text { Need for clear communication of } \\
\text { medical information: prognosis } \\
\text { regarding quality of life; risks, benefits } \\
\text { and alternatives of treatments } \\
\text { Trusting relationship with medical } \\
\text { team }\end{array}$ & $\begin{array}{l}\text { "My mother didn't have a [power of attorney] in place before } \\
\text { getting sick and I was the SDM, but the health care team treated } \\
\text { me as if they didn't think I had a right to be making decisions, so } \\
\text { this made it very difficult. I had to advocate on her behalf to the } \\
\text { medical team." (64-yr-old woman, health care professional) }\end{array}$ \\
\hline External influences on SDM & $\begin{array}{l}\text { Social and cultural barriers to } \\
\text { communication } \\
\text { Need for time and quiet setting } \\
\text { Previous training }\end{array}$ & $\begin{array}{l}\text { "I am more open than the rest of my family to having } \\
\text { conversations about end of life. Every time I try to initiate } \\
\text { conversations about their wishes, they stop me. They are not } \\
\text { open to discussing these kinds of things." (51-yr-old woman) }\end{array}$ \\
\hline Fears & $\begin{array}{l}\text { Fear of guilt after decision } \\
\text { High stakes/burden of responsibility }\end{array}$ & $\begin{array}{l}\text { "[Barriers include the] uncertainty of you making the final } \\
\text { decision for someone else ... [and the] responsibility of living } \\
\text { with that decision for the rest of your life. (40-yr-old man) }\end{array}$ \\
\hline
\end{tabular}

participants who believed that the skill of having a conversation with loved ones about values in critical illness was learnable, those who had previously had such a conversation and those who believed they would be a substitute decision-maker in the future (Figure 2). In a logistic regression, however, the only significant predictor was the belief that having conversations about values around end of life and critical illness was learnable (OR 2.57, 95\% CI 1.37-4.80) (Table 2). Conversely, compared to age 16-17, age 35-49 was a negative predictor (OR 0.07, 95\% CI 0.01-0.78).
Enablers and barriers associated with whether 16-yearolds should learn about being a substitute decision-maker in resuscitative and end-of-life care and representative quotations, by theme, are shown in Table 4 . Themes included the age appropriateness of teaching 16-year-olds, a potential developmental benefit, and an overall societal benefit in breaking taboos and raising awareness of what is a universal issue for an aging population. Participants also encouraged a nuanced approach respectful of different maturity levels, cultures, and individual experiences and readiness. 


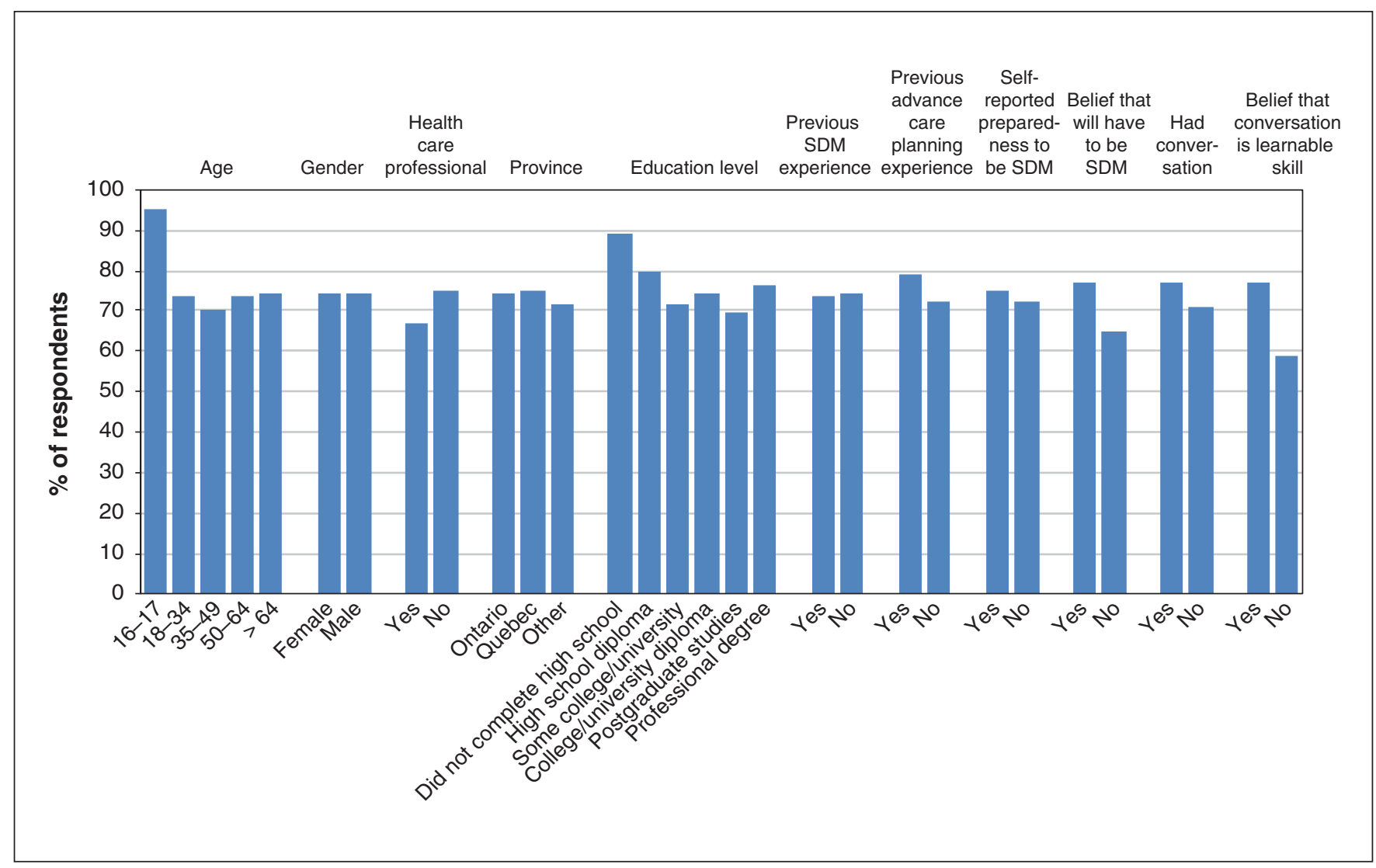

Figure 2: Rates of belief that 16-year-old students should learn about being a substitute decision-maker (SDM) in the context of critical illness. Note: conversation refers to conversation regarding wishes of loved ones in the event of critical illness or end of life.

\section{Interpretation}

About three-quarters of our respondents felt prepared to be a substitute decision-maker, but almost half reported never having had a meaningful conversation with their loved ones about their wishes in the event of critical illness. Lack of this crucial conversation - the key to a substitute decision-maker's understanding of the loved one's wishes, values and beliefs strongly suggests a discrepancy between actual and perceived preparedness. This gap has also been noted in previous work, where disagreements as to whether a conversation had even taken place were common. ${ }^{15}$

This discrepancy between actual and perceived preparedness has direct clinical implications. Physicians should take care to ensure that substitute decision-makers fully understand their role and base their understanding of the patient's wishes, values and beliefs on reasonably detailed conversations. Some of our respondents noted that it could be difficult to separate their own beliefs from the patient's, highlighting that physicians should inquire about the patient's wishes in such a way as to mitigate this risk. Ideally, before acute illness strikes, chronic care physicians should meet with the patient and his or her substitute decision-maker to ensure that the latter has a good understanding of the role of a substitute decision-maker and the patient's wishes should he or she become unable to communicate. Past work has shown that, although physicians trigger discussions regarding end of life and critical care when a patient's disease becomes severe, severity does not predict readiness for a discussion. ${ }^{16}$ Furthermore, members of the public generally welcome the opportunity to discuss their wishes, even when well. ${ }^{17}$

Previous Canadian studies showed that the greatest barriers to discussions regarding goals of care, as perceived by clinicians, were patient and family factors, especially "difficulty understanding the limitations/complications of life sustaining therapies, [and] lack of agreement among family members." 18,19 The public perspective in our study supports that patient, and family factors are major barriers to overcome. Although lacking medical knowledge was identified as a barrier by our respondents, multiple themes emerged regarding difficulty knowing how best to prepare for such a high-stakes life-altering event, including a fear of decision-making guilt, and a need to overcome sociocultural barriers and family conflict. Our findings underline the need for greater public education on these topics.

Many of the elements described by our participants as necessities to be a prepared substitute decision-maker have already been enshrined by provincial laws describing capacity, informed consent and decision-making in the best interest of the patient. Yet a common theme emerging from our interviews was a need for more effective communication to facilitate an effective relationship among health care providers, 
Table 4: Reported benefits and disadvantages of high school education

\begin{tabular}{|c|c|c|}
\hline Theme & Subtheme & Representative quotation \\
\hline Age appropriateness & $\begin{array}{l}\text { Existing experience within families } \\
\text { Legal right denotes societal } \\
\text { responsibility to prepare } \\
\text { Cognitive and emotional maturity } \\
\text { Subset of immature students who may } \\
\text { not be ready }\end{array}$ & $\begin{array}{l}\text { "I agree because I think that if someone can legally make a } \\
\text { decision, [he or she] should know all the information that comes } \\
\text { with that right. People are taught about sex at } 14 \text {; this is just as } \\
\text { important, and they are mature enough to understand this as } \\
\text { well." (18-yr-old woman) } \\
\text { "Some } 16 \text {-year-olds are pretty immature, and they would have to } \\
\text { be mature to be taught this." ( } 82-y \text {-old woman, health care } \\
\text { professional) }\end{array}$ \\
\hline Developmental benefit & $\begin{array}{l}\text { Improved decision-making } \\
\text { Increased sense of responsibility and } \\
\text { maturity } \\
\text { Development of personal beliefs }\end{array}$ & $\begin{array}{l}\text { "By } 16 \text { they understand that death happens.... They will walk out } \\
\text { of learning this and have bigger conversations with their friends } \\
\text { and family about this topic." (49-yr-old woman) }\end{array}$ \\
\hline $\begin{array}{l}\text { Decreases stress/distress at } \\
\text { time of decision }\end{array}$ & $\begin{array}{l}\text { Unpredictability in timing of real-life } \\
\text { situation }\end{array}$ & $\begin{array}{l}\text { "I had to make these decisions as a } 24 \text {-year-old. My mom, as a } \\
\text { health care provider, always let me know what she wanted. From } \\
\text { when I was young ( } 10 \text { and onwards) I felt equipped to support } \\
\text { her and her decisions when the time came regardless of my } \\
\text { personal feelings." ( } 43 \text {-yr-old woman) }\end{array}$ \\
\hline Societal benefit & $\begin{array}{l}\text { Universal issue - awareness needed } \\
\text { Breaking taboos } \\
\text { Taking care of parents }\end{array}$ & $\begin{array}{l}\text { "It's like sex ed - are you going to hide it from them? It's } \\
\text { important to have these conversations because they can be put } \\
\text { in this situation at any time. If you see your parents going } \\
\text { through it you might wonder what's going on, so it's good to be } \\
\text { educated on this topic. It shouldn't be a taboo subject." ( } 66 \text {-yr-old } \\
\text { man) }\end{array}$ \\
\hline $\begin{array}{l}\text { Potential difficulties/harm in } \\
\text { selected students }\end{array}$ & Mandatory v. opt in v. opt out & $\begin{array}{l}\text { "People are having kids later these days, and this could come up } \\
\text { sooner in a person's life. Someone could be an only child and } \\
\text { would need this [information]. No one is ever prepared for the } \\
\text { psychological and emotional stress that comes with this." } \\
\text { (47-yr-old man) }\end{array}$ \\
\hline Risk of bias & Teacher and facilitator dependent & $\begin{array}{l}\text { "[You] have to consider religious [implications], family members, } \\
\text { customs, language and country of origin." ( } 82 \text {-yr-old woman, } \\
\text { health care professional) }\end{array}$ \\
\hline
\end{tabular}

patients and substitute decision-makers, learn the preexisting wishes of loved ones and better negotiate family conflicts. This is consistent with previous work highlighting effective communication as the crucial element of end-of-life care. ${ }^{7,20,21}$ Ongoing emphasis on training of health care providers to improve communication is needed.

The Ontario government has prioritized "support for more public education about [advance care plans] so that patients' wishes for end-of-life care are understood,"22 with the auditor general underlining this as an unmet need. ${ }^{23}$ About one-third of our respondents had previously created advance care plans for themselves, consistent with low rates in previous Canadian studies. ${ }^{7,24}$ Qualitative studies in Canada and Australia showed that inaccessibility and lack of knowledge lead to fear, avoidance and mistrust when it comes to advance care planning. ${ }^{25,26}$ Although interventions to facilitate advance care planning continue, ${ }^{9}$ preparation to care for loved ones as a substitute decision-maker should be synergistic and provide more cues to action, as per the Health Belief Model. ${ }^{10}$ Three-quarters of our participants believed they would act as a substitute decision-maker in the future; the universality of this issue warrants consideration of population-based solutions.

The high school setting provides an opportunity for universal education. This is the ideal age group for education on resuscitation and end-of-life care, given that, in Canada, the law bestows the right to act as a substitute decision-maker on people at the age of 16-19 years, depending on the province or territory. Indeed, several participants described their experiences as a substitute decision-maker at a young age, including respondents as young as 18 . Most respondents $(71.9 \%)$ supported high school education around substitute decisionmaking. Some pioneers have begun to deliver such programs. Beccaro and colleagues ${ }^{27,28}$ have described a pilot program in Italy, and an intensive care physician has delivered classes and advocated for the idea in California. ${ }^{29}$ Future studies are needed on a national level with an eye toward eventual curriculum design.

\section{Limitations}

We minimized selection bias through our protocolled interception of every third person and choice of geographically and economically diverse sites. However, street intercept methodology is inherently biased toward active, healthy people. Our study population had higher proportions of young, female participants with postsecondary education than would be expected for Ottawa or Ontario. ${ }^{30}$ Among others, this underrepresents rural, elderly, impoverished and disabled people. We chose not to recruit participants in health care 
settings as substitute decision-makers include all people, not only those actively using health care services. Overall, the external validity of our findings to Ontario and Canada remains to be established. There is a self-serving and social desirability bias toward presenting oneself in a favourable way, i.e., reporting preparedness. ${ }^{31} \mathrm{It}$ is even more concerning that we identified a substantial gap in preparedness despite this. Finally, we were unable to collect income, rural residence and other variables of interest. Cultural differences are likely to affect family discussions regarding goals of care. However, many self-identify as hailing from multiple cultures, and it would be difficult to categorize a person into a single culture for a robust analysis.

\section{Conclusion}

Our study reveals a gap between actual and perceived preparedness to be a substitute decision-maker and highlights the need for clinicians to help families overcome barriers to effective substitute decision-making. This work also provides preliminary support for the development of a high school curriculum around these issues. We hope further efforts will help normalize the conversation around resuscitation, end-of-life care and death.

\section{References}

1. Consent to treatment. Ottawa: College of Physicians and Surgeons of Ontario; 2015. Available: www.cpso.on.ca/Physicians/Policies-Guidance/Policies/ Consent-to-Treatment (accessed 2018 June 28).

2. Wright AA, Zhang B, Ray A, et al. Associations between end-of-life discussions, patient mental health, medical care near death, and caregiver bereavement adjustment. 7AMA 2008;300:1665-73.

3. Zhang B, Wright AA, Huskamp HA, et al. Health care costs in the last week of life: associations with end-of-life conversations. Arch Intern Med 2009;169: 480-8.

4. Detering KM, Hancock $\mathrm{AD}$, Reade $\mathrm{MC}$, et al. The impact of advance care planning on end of life care in elderly patients: randomised controlled trial. BM7 2010;340:c1345

5. Silveira MJ, Kim SYH, Langa KM. Advance directives and outcomes of surrogate decision making before death. NEngl 7 Med 2010;362:1211-8.

6. Torke AM, Sachs GA, Helft PR, et al. Scope and outcomes of surrogate decision making among hospitalized older adults. 7AMA Intern Med 2014;174:370-7.

7. Heyland DK, Barwich D, Pichora D, et al.; ACCEPT (Advance Care Planning Evaluation in Elderly Patients) Study Team; Canadian Researchers at the End of Life Network (CARENET). Failure to engage hospitalized elderly patients and their families in advance care planning. 7AMA Intern Med 2013;173:778-87.

8. Heyland DK, Ilan R, Jiang X, et al. The prevalence of medical error related to end-of-life communication in Canadian hospitals: results of a multicentre observational study. BM7 Qual Saf 2016;25:671-9.

9. Abba K, Byrne P, Horton S, et al. Interventions to encourage discussion of end-of-life preferences between members of the general population and the people closest to them - a systematic literature review. BMC Palliat Care 2013;12:40.

10. Rosenstock IM. The health belief model and preventive health behavior. Health Educ Monogr 1974;2:354-86.

11. Seale H, Heywood AE, McLaws ML, et al. Why do I need it? I am not at risk! Public perceptions towards the pandemic (H1N1) 2009 vaccine. BMC Infect Dis 2010;10:99.

12. Cochran WG. Sampling techniques. 2nd ed. New York: John Wiley and Sons; 1963.

13. Dillman D, Smyth J, Christian L. Internet, phone, mail, and mixed-mode surveys: the tailored design method. 4th ed. Hoboken (NJ): Wiley-Blackwell; 2014.

14. Braun V, Clarke V. Using thematic analysis in psychology. Qual Res Psychol 2006;3:77-101.

15. Fried TR, Zenoni M, Iannone L, et al. Engagement in advance care planning and surrogates' knowledge of patients' treatment goals. 7 Am Geriatr Soc 2017; 65:1712-8.
16. Pfeifer MP, Mitchell CK, Chamberlain L. The value of disease severity in predicting patient readiness to address end-of-life issues. Arch Intern Med 2003; 163:609-12.

17. Marco CA, Larkin GL. Cardiopulmonary resuscitation: knowledge and opinions among the U.S. general public. State of the science-fiction. Resuscitation 2008;79:490-8.

18. You JJ, Downar J, Fowler RA, et al.; Canadian Researchers at the End of Life Network. Barriers to goals of care discussions with seriously ill hospitalized patients and their families: a multicenter survey of clinicians. FAMA Intern Med 2015;175:549-56.

19. You JJ, Aleksova N, Ducharme A, et al. Barriers to goals of care discussions with patients who have advanced heart failure: results of a multicenter survey of hospital-based cardiology clinicians. 7 Card Fail 2017;23:786-93.

20. Heyland DK, Dodek P, Rocker G, et al.; Canadian Researchers End-of-Life Network (CARENET). What matters most in end-of-life care: perceptions of seriously ill patients and their family members. CMA7 2006;174:627-33.

21. You JJ, Dodek P, Lamontagne F, et al.; ACCEPT Study Team and the Canadian Researchers at the End of Life Network (CARENET). What really matters in end-of-life discussions? Perspectives of patients in hospital with serious illness and their families. CMA7 2014;186:E679-87.

22. Palliative and end-of-life care. Toronto: Ministry of Health and Long Term Care; modified 2018 Dec. 7. Available: www.health.gov.on.ca/en/public/ programs/palliative/ (accessed 2018 June 28).

23. Palliative care - follow-up on VFM section 3.08. 2014 annual report of the Office of the Auditor General of Ontario. Chapter 1, section 1.08. Toronto: Queen's Printer for Ontario; 2016:98-108. Available: www.auditor.on.ca/en/content/ annualreports/arreports/en16/v2_108en16.pdf (accessed 2018 June 28).

24. Teixeira AA, Hanvey L, Tayler C, et al.; Canadian Researchers at End of Life Network (CARENET). What do Canadians think of advanced care planning? Findings from an online opinion poll. BM7 Support Palliat Care 2015;5:40-7.

25. McLennan VEJ, Boddy JHM, Daly MG, et al. Relinquishing or taking control? Community perspectives on barriers and opportunities in advance care planning. Aust Health Rev 2015;39:528-32.

26. Banner D, Freeman S, Kandola DK, et al. Community perspectives of end-oflife preparedness. Death Stud 2019;43:211-23.

27. Beccaro M, Gollo G, Ceccon S, et al. Students, severe illness, and palliative care: results from a pilot study on a school-based intervention. Am 7 Hosp Palliat Care 2015;32:715-24.

28. Beccaro M, Gollo G, Giordano M, et al. The Ligurian high-school educational project on palliative care: development and piloting of a school-based intervention on bereavement and severe illness. Am 7 Hosp Palliat Care 2014:31:756-64.

29. Zitter JN. First, sex ed. Then death ed. The New York Times. Available: www. nytimes.com/2017/02/18/opinion/sunday/first-sex-ed-then-death-ed.html?_r=0 (accessed 2018 June 28)

30. Census profile, 2016 census. Ottawa: Statistics Canada; modified July 8. Available: www12.statcan.gc.ca/census-recensement/2016/dp-pd/prof/index.cfm? Lang=E (accessed 2019 June 12).

31. Krumpal I. Determinants of social desirability bias in sensitive surveys: a literature review. Qual Quant 2013;47:2025-47.

Affiliations: Department of Emergency Medicine (Wong, Frank, Fischer, Cheung) and Faculty of Medicine (Medor, Yelle Labre), University of Ottawa, Ottawa, Ont.; Department of Family Medicine (Jiang), Temmy Latner Centre for Palliative Care, Sinai Health System, Toronto, Ont.

Contributors: Michael Wong conceived of the study. Michael Wong, Mengzhu Jiang, Jason Frank, Lisa Fischer, and Warren Cheung designed the study and survey. Michael Wong, Maria Medor and Katerina Labre designed the protocol to intercept participants and collected the data. Mengzhu Jiang conducted the statistical analysis, and Michael Wong and Warren Cheung conducted the qualitative analysis. Michael Wong drafted the manuscript. All of the authors critically revised the manuscript for important intellectual content, approved the final version to be published and agreed to act as guarantors of the work.

Funding: This study was internally funded by the Department of Emergency Medicine at the University of Ottawa.

Acknowledgement: The authors thank Angela Marcantonio for administrative support.

Supplemental information: For reviewer comments and the original submission of this manuscript, please see www.cmajopen.ca/content $/ 7 / 3 /$ E573/suppl/DC1. 